\title{
A arquitetura da informação em plataformas colaborativas como suporte para a gestão da inteligência coletiva nas organizações
}

\author{
Paulo César Rodrigues Borges \\ Roberto Mahmud Drumond Rhaddour
}

Universidade de Brasília - UnB, Brasil

\section{REVIEW}

\begin{abstract}
Resumo
Objetivo. Este artigo tem como objetivo apresentar uma maneira de aproveitar as possibilidades da segunda geração de comunidades e serviços na Internet (popularmente designada por Web 2.0) no desenvolvimento de uma arquitetura da informação em plataforma colaborativa por meio de uma Wiki, descrevendo a sua utilidade para transformação do conhecimento individualizado em conhecimento acessível e dinâmico nas organizações públicas.

Método. Para a organização deste estudo serão adotados procedimentos técnicos no sentido de fazer criterioso levantamento bibliográfico na literatura de referência, baseado na compilação de livros especializados, trabalhos publicados em periódicos e em outras bases de dados disponíveis.

Resultados. O artigo explora a Web 2.0 e desvenda as possibilidades de uma arquitetura da informação em plataforma colaborativa por meio de uma Wiki resultando em um melhor aproveitamento da inteligência coletiva nas organizações públicas.

Conclusões. Obteve-se a constatação de que as plataformas colaborativas em um modelo Wiki podem ser utilizadas como ferramenta para a transformação do conhecimento individualizado em conhecimento acessível e dinâmico, principalmente pela facilidade de uso.
\end{abstract}

Palavras-chave

Arquitetura da informação; Gestão do conhecimento; Inteligência coletiva; Web 2.0

Information architecture in collaborative platforms as a support for the management of collective intelligence in organizations

\begin{abstract}
Objective. This papper aims to present a way to take advantage of the possibilities of the second generation of communities and services on the Internet (popularly called Web 2.0) in the development of an information architecture in a collaborative platform through a Wiki, describing its usefulness for transformation of individualized knowledge in accessible and dynamic knowledge in public organizations.

Method. For the organization of this study, technical procedures will be adopted to make a careful bibliographic survey in the reference literature, based on the compilation of specialized books, papers published in periodicals and other available databases.

Results. The papper explores Web 2.0 and uncovers the possibilities of an information architecture on a collaborative platform through a Wiki resulting in a better use of collective intelligence in public organizations.

Conclusions. It was obtained the realization that the collaborative platforms in a Wiki model can be used as a tool for transforming individualized knowledge into accessible and dynamic knowledge, mainly for ease of use.
\end{abstract}

Keywords

Collective Intelligence; Information architecture; Knowledge management; Web 2.0. 


\section{Introdução}

Vive-se, hoje em dia, em um ambiente caracterizado por mudanças, intensa comunicação e troca de informações on-line. Isto faz com que as organizações públicas ou privadas tenham a necessidade de manter um aprimoramento contínuo em seus sistemas de informação para contar com a velocidade de resposta às mudanças ambientais e que tenham capacidade de inovar na forma com que mantêm suporte a estes sistemas. Parte-se do pressuposto de que as organizações estão de fato inseridas na chamada "sociedade da informação e do conhecimento", que reúne as novas diretrizes e novas orientações voltadas para o aprendizado, a competitividade, a colaboração e a inovação, onde o objeto "informação" é o principal recurso.

Nesta intensa troca on-line, o que não faltam são oportunidades de aproveitar dados disponíveis e criados pelas pessoas e, dentro do contexto de cada indivíduo, transformar esses dados em informação útil e em conhecimento, alavancando o crescimento organizacional. Lima-Marques e Macedo (2006) estabelecem que, no contexto organizacional, a geração e troca de informações e conhecimentos tornaram-se ações decisivas e a capacidade de gestão de recursos informacionais passou a ser um diferencial, definindo a produtividade e possibilitando a competitividade no mercado globalizado.

Os autores explicam que "a transformação eficiente e eficaz desses dados em conhecimento acessível, que possa resultar em melhor desempenho da organização, passa pelo domínio da arquitetura da informação" (LIMA-MARQUES; MACEDO, 2006, p. 241).

Macedo (2007) e Pérez-Montoro Gutiérrez (2010) apresentam a arquitetura da informação como um objeto de estudo clássico da Ciência da Informação. Esclarecem que a arquitetura da informação busca desenhar espaços informacionais que possibilitem o compartilhamento de informações, ao passo que a arquitetura tradicional busca a criação de estruturas em ambientes que viabilizem a convivência no mundo. Ambas possuem a mesma matéria prima: o "espaço" ou "ambiente", e servem às necessidades humanas, mesmo que de natureza diversa.

Constituindo a arquitetura da informação uma metodologia de "desenho", ela pode se aplicar a qualquer ambiente de informação e a qualquer tecnologia de suporte, inclusive a web. Tarapanoff e Alvares (2015) informam que a segunda geração de comunidades e serviços na Internet, popularmente designada por "Web 2.0" ou "Web Social", possibilitam análises de como a organização pode adaptar-se ao contexto da era digital em uma sociedade em rede.

Tarapanoff e Alvares (2015) ainda assinalam que o interesse da inteligência organizacional na "Web 2.0" recai sobre:

- $\quad$ as possibilidades de interação com seus usuários, em tempo real, por meio da utilização dessa plataforma;

- utilização do Big Data disponibilizado a partir da geração e troca de informações entre usuários, incluindo aqui as organizações, como base de análise;

- $\quad$ utilização de novas metodologias e ferramentas de acesso e recuperação da informação, disponíveis para a aplicação na plataforma da "Web 2.0"; e

- utilização de metodologias de diversas áreas das ciências humanas e sociais que têm como foco o indivíduo, as comunidades e as sociedade.

No âmbito das organizações públicas, o que se vê na maioria das vezes são dezenas de Sistemas de Informações (na verdade, grandes repositórios de dados) que, além de não se comunicarem entre si adequadamente, não estão disponíveis aos diversos usuários nos mais diferentes níveis, não favorecendo a recuperação da informação. Além disso, o grande volume, variedade e velocidade com que os dados são produzidos, dificultam sobremaneira a organização dos dados e impedem o acesso dinâmico e oportuno às informações. O que se verifica é que as organizações públicas não têm disponibilizado de forma significativa 0 conhecimento produzido para seu público interno e para a sociedade.

Assim, este artigo tem o intuito de explorar a segunda geração de comunidades e serviços na Internet (popularmente designada por Web 2.0), desvendando possibilidades de uma arquitetura da informação em plataforma colaborativa, por meio de uma Wiki, descrevendo a sua importância para o aproveitamento da inteligência coletiva nas organizações públicas. Apresenta, ainda, as possibilidades oferecidas pelas plataformas colaborativas em uma arquitetura no modelo Wiki, como ferramenta para a transformação do conhecimento individualizado em conhecimento acessível e dinâmico. 
Para cumprir este objetivo, foi realizado um levantamento bibliográfico na literatura de referência, baseado na compilação de livros especializados, trabalhos publicados em periódicos e em outras bases de dados disponíveis. Por meio da revisão de literatura, foi possível identificar os principais autores e o que já foi publicado sobre o objeto de estudo.

Com base nesse entendimento, a opção foi realizar uma pesquisa de natureza qualitativa na busca de entendimento dos fenômenos que ocorrem no campo da criação e gestão da inteligência coletiva.

\section{Fundamentação teórica}

Na Ciência da Informação, não há como dissociar a Arquitetura da Informação da Organização do Conhecimento. Para Hjorland (2012), os princípios de ambas se sobrepõem e, especialmente, a Organização do Conhecimento se vale das diversas possibilidades de mídias da Arquitetura da Informação para se fazer representar. Portanto, este artigo busca apresentar definições importantes para embasar a arquitetura da informação e sua importância para a gestão da inteligência coletiva nas organizações.

\subsection{A Ciência da Informação}

A construção colaborativa do conhecimento, sustentada por modernas ferramentas de tecnologias da informação e comunicação está no campo da Ciência da Informação, visto que contextualiza o estudo dos fluxos da informação desde a sua criação até a sua utilização, e a sua transmissão ao receptor, em uma variedade de formas, através de diversos canais.

Não se pretende trazer à discussão dezenas de definições sobre Ciência da Informação e suas características, tampouco buscar estabelecer conciliação e convergência para as definições. Para tal intento, seria necessário aprofundar as reflexões sobre as obras de Borko (1968), Wersig (1975), Belkin (1976), Le Coadic (2004) dentre outros importantes autores. A busca se ateve aos esclarecimentos iniciais que fornecessem sustentação à premissa de que a ciência da informação é a base científica para a criação de argumentos sobre arquitetura da informação e seu suporte facilitador para a gestão da inteligência coletiva.

E neste sentido, suficiente será compreender que a Ciência da Informação trata de um conjunto de conhecimentos relacionados com a origem, captação, organização, armazenamento, recuperação, interpretação, transmissão, transformação e utilização da informação. Em outras palavras, é a ciência que estuda a utilização da informação pelo ser humano e se ocupa da informação registrada, representada e todos os mecanismos que envolvem esta atividade.

\subsection{Dado, Informação, Conhecimento}

Dado, informação, conhecimento e mais além, inteligência, sabedoria, competência são termos de difícil definição ou conceituação devido à amplitude semântica e às diversas perspectivas de análise, domínios e concepções de cada área. Por mais primário que possa parecer, cabe neste ponto do trabalho destacar que dado, informação, conhecimento e inteligência não são sinônimos e entender a diferença e o momento de transição entre eles é primordial.

Num contexto organizacional, dados são utilitariamente descritos como registros estruturados de transações, que se transformam em informação, que é tudo aquilo que é processado pelo ser humano, podendo favorecer a obtenção do conhecimento.

Para Davenport e Prusak (2003), informação é uma mensagem que na maioria das vezes se apresenta como um documento ou uma comunicação audível ou visível. A informação não só dá forma ao receptor como ela própria tem uma forma: ela está organizada para alguma finalidade.

Já o conhecimento, está relacionado com os aspectos cognitivos que ocorrem na mente humana e envolvem processos mentais de captação, assimilação, associação e também construção, desconstrução e reconstrução de conceitos. Ele acontece na percepção de cada indivíduo em função de diversos aspectos, sejam eles culturais, sociais, temporais, religiosos e outros relacionados à maneira de ver e compreender o mundo. "O 
conhecimento, nesse caso, é subjetivo (inerente ao sujeito), mas ao mesmo tempo social, pois o ser humano interage com o mundo que o circunda, modificando-o e sendo por ele modificado". (LIMA E ALVARES, 2012, p. 25). Setzer (2015) acrescenta que conhecimento não pode ser descrito e sim, a informação (se for entendida pelo receptor).

Outra dimensão de significado da palavra "conhecimento" envolve o aspecto do conhecimento acumulado ao longo do tempo e da sua socialização e compartilhamento, facilitados pelo contexto atual da era digital em da sociedade em rede que vivemos. Este conhecimento subjetivo é o que alavanca e proporciona a competência, isto é, "a capacidade de executar uma tarefa no mundo real" (SETZER, 2015, p.3).

\subsection{A arquitetura da informação facilitando a gestão da informação e do conhecimento}

Percebe-se, desde o século passado, com a chamada "era" ou "sociedade" da informação, que grandes máquinas foram substituídas paulatinamente pelos computadores; o trabalho manual pelo trabalho intelectual; e a produção de bens materiais começou a ser menos valorizada do que a produção de dados e informações. Cada vez mais é percebida a crescente velocidade com que novos dados são produzidos, circulando quase que instantaneamente de forma incontrolável devido às facilidades oferecidas pelas tecnologias modernas. Então, tirar proveito de tamanha quantidade de informações é a nova tendência e falar sobre a importância estratégica disto torna-se de certa forma óbvio. O que se põe em relevo, então, é o entendimento de que grande parte desses recursos informacionais é produzida na própria organização. E sobre os recursos informacionais, Araújo Júnior et al. (2015, p. 46) orientam que:

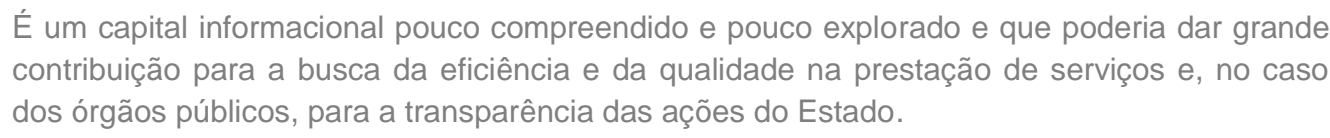

Davenport e Prusak (2003) tratam de forma pormenorizada a maneira que as organizações gerenciam a informação e o conhecimento. Os referidos autores elucidam que, a despeito de inúmeras teorias, modismos, novas tecnologias e fórmulas mágicas, o que de verdade alimenta o funcionamento de uma organização é o que seus funcionários sabem. As pessoas e seus conhecimentos são o que movem a organização. Portanto, a gestão do conhecimento é responsável pelo gerenciamento do ativo intangível produzido na organização. Atua junto aos fluxos informais e tem como foco o capital intelectual da organização.

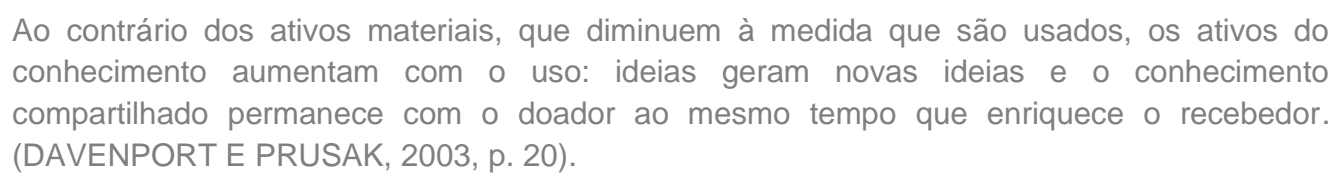

De acordo com Choo (2003, p.30), "o conhecimento reside na mente dos indivíduos, e esse conhecimento individual precisa ser convertido em conhecimento que possa ser compartilhado e transformado em inovação".

É nesse cenário que se visualiza a arquitetura da informação como facilitadora da gestão de tamanha complexidade de ativos. Ela surge como a arte de expressar um modelo ou conceito de informação utilizado em atividades que exigem pormenores explícitos de sistemas complexos.

Como uma série de outras definições já mencionadas neste texto, a definição de Arquitetura da Informação também não é consensual. Porém, especialmente neste caso, não há como falar em Arquitetura da Informação sem mencionar Richard Saul Wurman, que "criou" o termo na década de 70. A definição oferecida por Wurman é:
(1) o indivíduo que organiza os padrões inerentes aos dados, tornando o complexo claro. (2) uma pessoa que cria a estrutura ou mapa de informações que permite que outros encontrem seus caminhos pessoais para o conhecimento. (3) a ocupação profissional emergente do século XXI que aborda as necessidades da era focada na clareza, na compreensão humana e na ciência da organização da informação. (WURMAN apud DING; LIN, 2010, p. 1).

Wurman explica de forma simples que a palavra arquiteto é utilizada para designar aquele que se ocupa da criação de princípios sistêmicos, estruturais e ordenados para fazer algo funcionar. Considera que o trabalho dos arquitetos de informação é focado em tornar o complexo claro, por meio de uma melhor organização e apresentação de informações. 
Outra importante referência é Morville e Rosenfeld (2006) que adotaram um enfoque multiperspectiva para definir a arquitetura da informação:

- o projeto estrutural de ambientes de informação compartilhada;

- a combinação de organização, rotulagem, pesquisa e navegação dentro de sites ou intranets;

- a arte e a ciência de moldar produtos de informação e experiência para dar suporte à usabilidade e localização; e

- uma disciplina emergente e comunidade de prática focada em trazer princípios de design e arquitetura para o ambiente digital (MORVILLE; ROSENFELD, 2006, p. 4).

Pode-se entender que o espírito da arquitetura da informação está bem representado na quarta definição, quando os autores afirmam que ela traz princípios de design e arquitetura para a paisagem digital. Também explica por que a Arquitetura da Informação se tornou uma disciplina no ambiente da web, embora o trabalho relacionado com arquitetura da informação estivesse muito antes da era web.

Dentro desse enfoque multiperspectiva em um ambiente digital, Rosenfeld, Morville e Arango (2015) esclarecem que é necessário entender e relacionar três elementos principais: contexto, conteúdo e usuário.

Rosenfeld, Morville e Arango (2015) explicam que o "contexto" reflete a cultura, a política, os objetivos, as tecnologias e os recursos disponíveis para o desenvolvimento dos produtos ou serviços. Saber quem são seus "usuários" tornará possível identificar o público alvo, suas necessidades de informação, que tipo de linguagem deve ser utilizada e qual o comportamento de busca de informações de modo a facilitar a utilização e navegação nesse ambiente digital. Somente conhecendo esses dois elementos será possível definir as formas de apresentação dos "conteúdos".

Porém, é importante observar o que orienta Pérez-Montoro Gutiérrez (2010), quando esclarece que a arquitetura da informação não deve ser confundida com a gestão de conteúdo ou gestão de conhecimento. Ao contrário da arquitetura, a gestão de conteúdo é responsável pelo desenvolvimento de estratégias abrangentes (conceituais e práticas) para o gerenciamento correto de conteúdo digital, enquanto a gestão de conhecimento busca o desenho de estratégias para aproveitar sistematicamente o conhecimento envolvido em uma organização.

Atualmente, o que se exige da arquitetura da informação é a possibilidade de oferecer espaços conectados, enfatizando o papel cada vez mais relevante da transmissão de conhecimentos entre as pessoas por intermédio na web. E neste ponto, é trazida à tona a colocação de Choo (2003), quando disse:

A construção do conhecimento é conseguida quando se reconhece o relacionamento sinérgico entre o conhecimento tácito e o conhecimento explícito dentro de uma organização, e quando são elaborados processos sociais capazes de criar novos conhecimentos por meio da conversão do conhecimento tácito em conhecimento explícito [...] As organizações precisam aprender a converter o conhecimento tácito, pessoal, em conhecimento explícito, capaz de promover a inovação e o desenvolvimento de novos produtos. (CHOO, 2003, p.37).

\section{A inteligência coletiva e a "WEB 2.0"}

A representação e organização da inteligência coletiva em ambientes digitais têm sido discutidas frequentemente. Abrem-se novos campos de pesquisa envolvendo a Ciência da Informação e o estudo conceitual e prático em gestão da inteligência coletiva.

O aproveitamento da inteligência coletiva, aqui discutido, se dá com o compartilhamento e a criação conjunta do conhecimento. Lévy (2015) define inequivocamente inteligência coletiva:

é uma inteligência distribuída por toda parte, incessantemente valorizada, coordenada em tempo real, que resulta em uma mobilização efetiva das competências. Acrescentamos à nossa definição este complemento indispensável: a base e objeto da inteligência coletiva são o reconhecimento e o enriquecimento mútuo das pessoas [...]. (LÉVY, 2015, p.29). 
A coordenação dos inteligentes coletivos ocorre com a utilização das tecnologias da informação e comunicação que, atualmente, repousa sobre inúmeras possibilidades pelo uso da Internet (ou ciberespaço, com sugere Lévy). Como exemplo de aproveitamento da inteligência coletiva, temos o processo colaborativo Wikipédiaß, a enciclopédia construída por meio de colaboração livre e gratuita de inúmeras pessoas, pelo simples prazer de fazer uma coisa útil (figura 1).

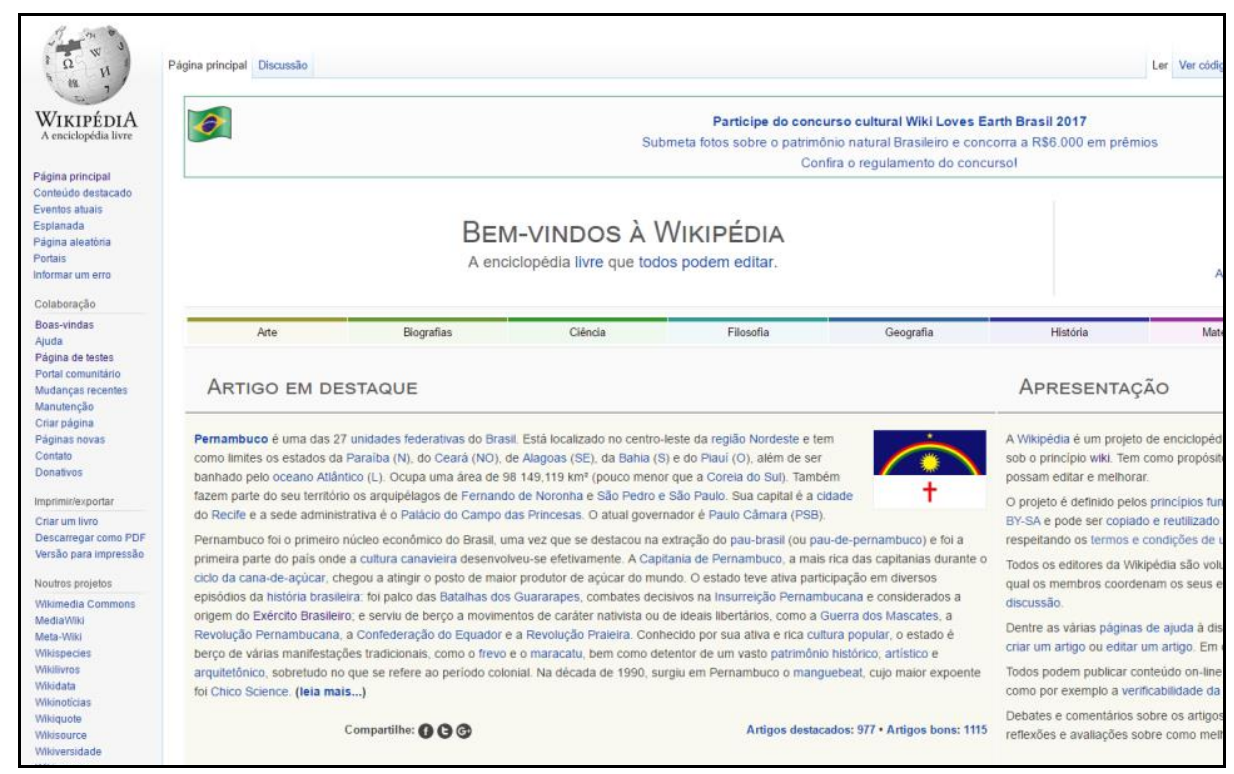

Figura 1 - Página da Wikipedia® na internet.

Fonte: Wikipédia®.

Portanto, o reconhecimento e o enriquecimento mútuos das pessoas são os pilares do conceito de inteligência coletiva, pois ela cria a perspectiva de um laço social construtivo e colaborativo, em que cada um pode colaborar com aquilo que sabe. Nesse cenário, a web surge como veículo para fazer com que de fato isto seja possível, principalmente as novas aplicações da web, que trouxeram essa nova dimensão da comunicação.

Como se sabe, a World Wide Web (WWW) é uma forma pela qual a informação pode ser difundida pela Internet. É um espaço "público" que permite a circulação de todo o tipo de informação, seja ela texto, imagem, sons, gráficos, vídeos etc.

Inicialmente, a web era estática e servia para disponibilizar conteúdos onde o utilizador final não podia alterá-los. Em regra, as páginas eram grandes aglomerados de hiperlinks do tipo "somente leitura", não existindo interatividade construtiva entre o criador da página e o usuário. Esta geração da Internet é comumente conhecida como Web 1.0. Desde então, a web cresceu a um ritmo exponencial e sofreu transformações. Não significa dizer que muitas organizações não tenham, atualmente, suas páginas plenamente hospedadas em um modelo Web 1.0 .

O mais importante aqui é que, independentemente da web ter crescido em tamanho (volume de dados, páginas indexadas por motores de busca etc), o que se percebe é a mudança na dinâmica de como a informação é produzida, captada, organizada, armazenada, recuperada, interpretada, transmitida, transformada e, por fim, utilizada. Esta mudança de dinâmica em que as tecnologias e aplicações são projetadas com o objetivo de realçar a criatividade, a informação coletiva e, sobretudo, a colaboração entre usuários foi batizada como Web 2.0, por Tim O’Reilly, criador do termo em 2005.

$\mathrm{Na}$ ocasião, Tim O'Reilly definiu a Web 2.0 como uma rede como como plataforma, abrangendo todos os dispositivos conectado, cujas aplicações são aquelas que aproveitam ao máximo as vantagens intrínsecas da plataforma. A Web 2.0 entrega o software como um serviço continuamente atualizado, que fica melhor à medida que mais pessoas o usam, consumindo e recombinando dados de múltiplas fontes, incluindo usuários individuais, fornecendo seus próprios dados e serviços em uma forma que permite edição por outros, criando efeitos de rede através de uma "arquitetura de participação". 
Até hoje, muitos outros autores que utilizam o termo Web 2.0 (CHAVES et al, 2015, TARAPANOFF \& ALVARES, 2015; LOPES, 2012; KEYES, 2012; HARARI \& SGANZERLA,2011; ANDRADE et al, 2011) convergem na definição dada por Tim O'Reilly em 2005 e, sem exceção, trazem a questão primordial de que a web evoluiu de acordo com o aumento da sua socialização.

O'Reilly (2006), Lopes (2012), Tarapanoff e Alvares (2015) explicam que a Web 2.0 significa a mudança para uma Internet como plataforma. Entre outras, a regra mais importante é desenvolver aplicativos que aproveitem os efeitos de rede para se tornarem melhores quanto mais são usados pelas pessoas, aproveitando a inteligência coletiva.

Tarapanoff e Alvares (2015) e Lopes (2012) destacam que a Web 2.0 apresentam a ideia da web como uma plataforma de trabalho, reforçando as práticas que irão permitir a gestão da Inteligência Coletivae e a valorização das experiências entre os usuários.

A chamada Web 2.0 é mais dinâmica, interativa, participativa e democrática, possibilitando a troca de informações e colaboração entre os usuários. Essa "nova versão" da internet possibilitou o surgimento de ferramentas como os blogs, microblogs, moblogs, videosharing, wikis, facdebook, instagram etc cuja arquitetura da informação é trabalhada de forma distinta.

Acredita-se que o advento da Web 2.0 seja a solução para muitas barreiras no compartilhamento de informações. Grace (2009) cita em seu artigo que muitas organizações como a IBM, a General Electric, a Procter \& Gamble, a Shell e a Airbus abandonaram sistemas de gestão de conhecimento complicados em favor de aplicações Web 2.0, tais como blogs, wikis e outras aplicações da web social.

\section{Um local de trabalho Wiki}

As wikis são páginas comunitárias publicadas na web, que podem ser alteradas por todos os usuários com direito de acesso. Harari e Sganzerla (2011) orientam que as wikis utilizadas em empresas tornam-se uma forma centralizada de trocar ideias em grupos de trabalho e um novo modelo para fazer gestão de conhecimento, facilitando a organização de tudo aquilo que os funcionários conhecem e que é necessário guardar e sistematizar para que o conhecimento não se perca.

O primeiro Wiki foi desenvolvido por Ward Cunningham em 1995. O seu WikiWikiWeb permitia que os desenvolvedores de software criassem uma biblioteca de padrões.

O nome "Wiki" foi inspirado na palavra havaiana Wiki (ou wiki-wiki) que significa "rápido". Pela web também transitam hipóteses de que o termo Wiki é um acrônimo de What I Know Is.

Leuf e Cunningham (2001) definem uma Wiki como uma coleção livremente expansível de páginas web interligadas, ou seja, um sistema de hipertexto para modificar e armazenar informações - um banco de dados onde cada página é facilmente editável pelos usuários. Em termos práticos, uma Wiki é um espaço de colaboração, de total liberdade, facilidade de uso e acesso, convenções de navegação simples e uniformes. É uma página da web que permite aos usuários excluírem, editarem e adicionarem conteúdo em um navegador.

Ainda segundo Leuf e Cunningham (2001), as características das Wikis são:

- edição fácil, pois os usuários não são obrigados a conhecer HTML ou linguagens de script;

- links e referências a outros sites relacionados a termos mencionados no Wiki, para ajudar os visitantes a entender melhor o contexto;

- mudança de rastreamento, muitas vezes na linha individual, palavra ou mesmo personagem, criando uma trilha de auditoria minuciosa de quem mudou o que; e

- função de pesquisa incorporada.

O quadro 1 apresenta apenas algumas Wikis que exemplificam ferramentas de gestão da inteligência coletiva. Existem, ainda, diversas outras ferramentas de suporte à colaboração e gestão da inteligência coletiva, como é 
o caso do Ideahunting.net, a plataforma SciPort, a rede de compartilhamento FormSpring do Banco Santander, o Ciencia 2.0 etc.

\begin{tabular}{|c|c|c|}
\hline Wiki & Endereço eletrônico & Propósito \\
\hline Wikiversity & $\begin{array}{l}\text { https://en.wikiversity.org/wiki/Wik } \\
\text { iversity:Main_Page }\end{array}$ & $\begin{array}{l}\text { Dedicado à aprendizagem e pesquisa para uso da pré- } \\
\text { escola até a universidade, incluindo treinamento } \\
\text { profissional e aprendizagem informal. Professores, } \\
\text { estudantes e pesquisadores se juntam na criação de } \\
\text { recursos educacionais abertos e colaborativos } \\
\text { comunidades de aprendizagem. }\end{array}$ \\
\hline Wikibooks & $\begin{array}{l}\text { https://en.wikibooks.org/wiki/Mai } \\
\text { n_Page }\end{array}$ & $\begin{array}{l}\text { Coleção de livros didáticos de conteúdo aberto que } \\
\text { qualquer pessoa pode editar. }\end{array}$ \\
\hline Wikivoyage & $\begin{array}{c}\text { https://en.wikivoyage.org/wiki/M } \\
\text { ain_Page }\end{array}$ & $\begin{array}{c}\text { Guia de viagem mundial gratuito que qualquer pessoa } \\
\text { pode editar }\end{array}$ \\
\hline $\begin{array}{l}\text { Center for Collective } \\
\text { Intelligence do } \\
\text { Massachusetts Institute of } \\
\text { Technology - MIT }\end{array}$ & http://cci.mit.edu/ & $\begin{array}{l}\text { Reunir professores de todo o MIT para realizar } \\
\text { pesquisas sobre como novas tecnologias de } \\
\text { comunicação estão mudando a maneira como as } \\
\text { pessoas trabalham juntas. }\end{array}$ \\
\hline
\end{tabular}

Quadro 2 - Exemplos de Wikis em atividade.

Fonte: elaborado pelo autor.

\subsection{Uma Wiki em uma organização pública}

O que se vê na maioria das organizações públicas, são dezenas de sistemas de informações (na verdade, grandes repositórios de dados), grande parte indisponíveis aos diversos usuários nos mais diferentes níveis. A recuperação da informação (ou dados) alojados nesses grandes sistemas não é favorecida. Além disso, o grande volume, variedade e velocidade com que os dados são produzidos, dificultam sobremaneira a sua organização e impedem o acesso dinâmico e oportuno.

Percebe-se, então, que as organizações públicas não têm disponibilizado de forma significativa o conhecimento produzido. Os servidores que se integram à organização poderiam possuir maior facilidade de acesso às informações necessárias à condução de suas atividades. Ao mesmo tempo, os servidores mais experientes em razão do tempo de permanência nas funções, poderiam oferecer aquilo que designamos por conhecimento tácito. E mais além: a sociedade se recente de velocidade de resposta aos seus interesses.

Nesse cenário, surge a oportunidade oferecida pelas Wikis. Grace (2009) ressaltou em seu estudo que há muitos benefícios associados ao uso de Wikis, como o seu enfoque ascendente (de baixo para cima) e informal, além da capacidade de construir uma cultura de confiança. A autora também assinalou um benefício significativo encontrado pelas organizações que usam Wikis: a capacidade de economizar tempo. Estes incluem o tempo economizado no treinamento de funcionários sobre o uso de Wikis versus um sistema de gestão altamente técnico, tempo economizado em viagens de longas distâncias para reuniões e colaboração entre gestores, redução do tempo gasto com a troca de e-mails. Pode-se acrescentar, ainda, o tempo gasto pelo cidadão que busca as organizações públicas demandando informações de toda ordem.

Annahi (2015) dá ênfase ao fato de que reter conhecimento organizacional, incentivar o compartilhamento de informações e integrar colegas de trabalho são algumas das razões que fazem as organizações decidirem implantar um Wiki Corporativo.

A seguir, Annahi (2015) elenca 5 dicas para o sucesso na implantação de um Wiki Corporativo:

Massa crítica: não adianta apenas um colaborador elaborar textos no Wiki. É preciso incentivar de forma correta todos os colaboradores a criar documentos, alimentando o sistema. Neste ponto, vale salientar que o colaborador deve ter a percepção de que irá doar e ter algo a receber em troca.

Cultura: é necessário observar, antes da implantação, se a organização tem uma cultura colaborativa, se os funcionários têm o costume de compartilhar informações e conhecimento entre eles. Para que funcione, é 
preciso investir em campanhas para incentivar maior colaboração entre todos, entendendo a importância e os benefícios do Wiki.

- Atualização: o Wiki deve ser constantemente atualizado, tanto com novos documentos como com documentos editados, de acordo com as mudanças atuais daquele assunto.

- Administração: por mais que todos os colaboradores devam ter liberdade para criar e editar os documentos do Wiki, é necessário que exista um gestor responsável pelo site, de preferência da área de TI.

- Investimento: não é necessário um alto investimento para implantar um Wiki Corporativo. Existem diversos softwares gratuitos, como por exemplo o MediaWiki, MoinMoin Wiki Engine e Twiki.

\section{Conclusões}

Neste trabalho procurou-se de forma simples e objetiva apresentar a utilização da arquitetura da informação em plataformas colaborativas como suporte para a gestão da inteligência coletiva nas organizações. A segunda geração de comunidades e serviços na Internet (popularmente designada por Web 2.0) certamente trouxe modernas possibilidades de trabalhar uma arquitetura da informação em plataforma colaborativa, neste caso, por meio de uma Wiki.

Graças às novas formas de comunicação e interação entre as pessoas e às novas tecnologias disponíveis com a evolução da web, as organizações sofreram uma grande mudança, principalmente na maneira de fazer a gestão do conhecimento.

As organizações precisam lidar de forma inovadora com as informações. Essas tecnologias (ditas redes sociais) que se usam no dia a dia estimulam e possibilitam maior colaboração entre as pessoas, materializando os conceitos que foram apresentados sobre o trabalho colaborativo e a gestão da inteligência coletiva, que se tornam viáveis por meio das Wikis.

Sendo as Wikis páginas comunitárias publicadas na web, elas podem ser alteradas por todos os usuários e estão se tornando uma maneira centralizada de trocar ideias em grupos de trabalho e um novo modelo para fazer gestão de conhecimento, facilitando a organização de tudo aquilo que os funcionários conhecem. Elas possibilitam a transformação do conhecimento tácito em conhecimento explícito. O uso destas ferramentas no ambiente organizacional iniciou um processo de quebra de paradigmas, visto que os gestores têm percebido o seu crescente potencial de colaboração. Elas fortalecem as estratégias informacional e comunicativa, ao trazer melhoria para a condução dos processos. Além disso, as Wikis revelam fortes benefícios organizacionais, à medida que podem ser utilizadas na obtenção, na organização, armazenamento, na recuperação e distribuição da informação.

Claro se torna que em nenhum momento foi proposta a substituição dos chefes, líderes e especialistas, propagadores de conhecimento nas organizações. O que se percebe é que o poder de concentração de conhecimento dá lugar, sistematicamente, a iniciativas que trabalham com a inteligência coletiva, porque o que se demonstrou foi que o saber está centrado nas pessoas e, por indução, na sociedade. Nas palavras de Levy (2014, p. 29), "Ninguém sabe tudo, todos sabem alguma coisa, todo o saber está na humanidade". 


\section{Referências}

ANNAHI, C. 5 ótimas dicas para um Wiki de sucesso! Portal gestão de pessoas e tecnologia da informação. 2015. Disponível em: <https://unisalgp.wordpress.com/2015/06/05/5-otimas-dicas-para-um-wiki-de-sucesso/>. Acesso em: 2 jun. 2017.

ANDRADE, I. A. et al. Inteligência coletiva e ferramentas WEB 2.0: a busca da gestão da informação e do conhecimento em organizações. In: Perspectivas em Gesto \& Conhecimento. João Pessoa, v.1, número especial, p. 27-43, Out. 2011. Disponível em: <http://periodicos.ufpb.br/ojs2/index.php/pgc/article/view/10385/6101> Acesso em: 10 abr. 2017.

ARAÚJO JR., R. H. de.; SOUSA, R. T. B. de.; ALBUQUERQUE, S. F. de. Métodos, Técnicas e Instrumentos de Organização e Gestão da Informação nas Organizações. In: BAPTISTA, D. M.; ARAÚJO JR., R. H. de. (Org.). Organização da Informação: abordagens e práticas. Brasília, DF: Thesaurus, 2015, p. 44-68.

BORKO, H. Information science: what is it? American Documentation, v. 19, n.1, p. 3-5, jan. 1968.

CHAVES, M. S. et al. Tecnologias da informacao da web 2.0 em empresas e na gestao de projetos: analise e uma agenda de pesquisa. Iberoamerican Journal of Project Management, Buenos Aires, v.6, n.1, A.R.B., p.23-46, 2015.

CHOO, C. W. A organização do conhecimento: uma visão holística de como as organizações usam a informação. In: Como as organizações usam a informação para criar significado, construir conhecimento e tomar decisões. São Paulo: Editora Senac, p. 27- 61,2006

CAPURRO, R.; HJORLAND, B. O conceito de informação. Perspectivas em ciência da informação. Belo Horizonte, v. 12, n. 1 , p. 148-207, 2007.

DAVENPORT, T. H.; PRUSAK, L. Conhecimento Empresarial, como as organizações gerenciam o seu capital Intelectual: métodos e aplicações práticas. 9. ed. Rio de Janeiro: Campus, 2003.

DING, W; LIN, X. Information Architecture: The Design and Integration of Information Spaces. University North Carolina (USA): Morgan \& Claypool Publishers, 2010.

GRACE, T. P. L. Wikis as a knowledge management tool. Journal of Knowledge Management, vol. 13. n.4, p.64-74, 2009. Disponível em: <http://www.emeraldinsight.com/ doi/abs/10.1108/13673270910971833>. Acesso em: 13 maio. 17.

HARARI, L. H.; SGANZERLA, R. Web 2.0 - A Era da Participação e Colaboração Coletiva. 2011. Blog Roberto Sganzerla. Disponível em: <http://www.robertosganzerla. com.br/2011/10/257/>. Acesso em: 06 jun. 17.

HJØRLAND, B. Is Knowledge Organization = Information Organization? In: International ISKO Conference Mysore, n. 12, 2012. Índia. Disponível em: <http://www.isko.org/cyclo /knowledge organization>. Acesso em: 06 jun. 17.

KEYES, J. Enterprise 2.0: social networking tools to transform your organization. Boca Raton: CRC Press, 2012.

LE COADIC, Y. Ciência da Informação. 2. ed. Brasília, DF: Briquet de Lemos, 2004.

LEUF, B.; CUNNINGHAM, W. The Wiki Way: Quick Collaboration on the Web. Addison-Wesley Longman, Glen View, IL. 2001.

LÉVY, P. A inteligência coletiva: por uma antropologia do ciberespaço. 10. ed. São Paulo: Edições Loyola, 2015.

LIMA-MARQUES, M.; MACEDO, F. L. O. de. Arquitetura da Informação: base para a gestão do conhecimento. In: TARAPANOFF, K. (Org.). Inteligência, Informação e Conhecimento em corporações. Brasília, DF: IBICT, UNESCO, 2006, p. 231-245.

LIMA, J. L. O.; ALVARES, L. Organização e representação da informação e do conhecimento. In: Alvares Lillian (org.). Organização da informação e do conhecimento: conceitos, subsídios interdisciplinares e aplicações. São Paulo: B4 Ed, p. 2147, 2012.

LOPES, L. C. J. A. A Web como ferramenta para a construção da Inteligência Coletiva. 2012. 69 f. Dissertação (Mestrado em Informação, Comunicação e Novas Mídias). Universidade de Coimbra. Portugal, 2012.

MACEDO, F. L. O. de. Arquitetura da Informação na Prática: Portais corporativos. 2007. Disponível em: <http://www.stf.jus.br/ arquivo/sijed/07.pdf>. Acesso em: 10 abr. 2017.

O'REILLY, T. Web 2.0: compact definition? Disponível em: <http://radar.oreilly.com/2005/10/web-20-compact-definition. html>. Acesso em: 23 abr. 2017.

Web 2.0 compact definition: trying again. Disponível em: <http://radar.oreilly.com/2006/12/web-20-compact-definitiontryi.html>. Acesso em: 23 abr. 2017.

PÉREZ-MONTORO GUTIÉRREZ, M. Arquitectura de la información en entornos web. Gijón: Trea, 2010.

ROSENFELD, L.; MORVILLE, P. Information Architecture for the World Wide Web. 3. ed. USA: O'Reilly, 2006. 
ROSENFELD, L.; MORVILLE, P; ARANGO, J. Information Architecture: For the Web and Beyond. 4. ed. Sebastopol: O'Reilly, 2015.

SETZER, W. Dado, Informação, Conhecimento e Competência. USP. 2015. Disponível em: <https://www.ime.usp.br/ vwsetzer /dado-info.html>. Acesso em: 11 jun. 2017.

TAPSCOTT, D.; WILLIAMS, A. D. Wikinomics: como a colaboração em massa pode mudar e seu negócio. Rio de Janeiro: Nova Fronteira, 2007.

TARAPANOFF, K. Inteligência Organizacional e Competitiva. Brasília, DF: Editora UnB, 2001.

TARAPANOFF, K (Org). Inteligência, informação e Conhecimento em corporações. Brasília, DF: IBICT, UNESCO, 2006.

TARAPANOFF, K.; ALVARES. L. Perspectivas em inteligência organizacional e competitiva na Web 2.0: uma visão geral. In: TARAPANOFF, K. (Org.). Análise da informação para tomada de decisão: desafios e soluções. Curitiba, PR: Intersaberes, $p$. 21-60, 2015.

WERSIG, G., NEVELING, U. The phenomena of interest to information science. The Information Scientist. v.9, n.4, 1975.

WURMAN, R. S. Information Architects. Zurich, Switzerland: GraphisPress, 1996.

\section{Dados dos autores}

\section{Paulo César Rodrigues Borges}

Doutor em Ciência da Informação pela Universidade de Brasília (2003). Doutor em Planejamento Estratégico pela Escola de Comando e Estado-Maior do Exército (1997). Mestre em Sistemas e Computação pelo Instituto Militar de Engenharia (1993). Engenheiro Cartógrafo pelo Instituto Militar de Engenharia (1987). Atualmente professor e pesquisador. Integrante do Grupo de Pesquisa R.E.G.I.I.M.E.N.T.O da UnB - Arquitetura da Informação, Linguística Computacional e Multimodalidade, Mídias e Interatividade.

\section{pcrborges@yahoo.com.br}

\section{Roberto Mahmud Drumond Rhaddour}

Mestrando do Programa de Pós-graduação em Ciência da Informação da Universidade de Brasília. Especialista em Gestão pela Escola de Instrução Especializada do Exército (2016). Especialista em Análise e Projeto de Sistemas pela Universidade Católica de Brasília (2001). Especialista em Aplicações Complementares às Ciências Militares pela Escola de Administração do Exército (1998). Bacharel em Estatística pela Universidade do Estado do Rio de Janeiro (1996). Integrante do Grupo de Pesquisa R.E.G.I.I.M.E.N.T.O da UnB - Arquitetura da Informação, Linguística Computacional e Multimodalidade, Mídias e Interatividade.

\section{drumond.roberto@gmail.com}

Recebido - Received: 2017-08-09

Aceitado - Accepted: 2018-01-11

\section{$(\mathrm{cc}) \mathrm{EY}$}

This work is licensed under a Creative Commons Attribution 4.0

United States License.

\section{ULIS D-Sente}

This journal is published by the University Library System of the University of Pittsburgh as part of its D-Scribe Digital Publishing Program and is cosponsored by the University of Pittsburgh Press. 